\title{
Flat feet, prone feet, posture and dependency between them in first grade children
}

\author{
Darina Zaharieva \\ From 11th International Conference on Conservative Management of Spinal Deformities - SOSORT 2014 \\ Annual Meeting \\ Wiesbaden, Germany. 8-10 May 2014
}

\section{Background}

Posture is simply the position our bodies adopt in response to the effects of gravity. It is the way we hold ourselves, in sitting, standing or even lying down. Correct posture gives not only a smart appearance but also helps to prevent injury and illness of the spine. The children's ankle-foot complex pass through various stages of development. The presence of abnormalities in them would be a logical prerequisite for the development of abnormalities in other parts of the children's body.

\section{Aim}

To establish frequency of flat feet, prone feet and posture and dependency between them in first grade children. The outcome of this assessment will be used to determine the choice of exercises that may improve the deficits discovered during the assessment.

\section{Methods}

31 girls and 27 boys mean age 7 years old were studied in October and November 2012. For the purposes of that study we used: posture assessment, ankle-foot complex assessment, pedobarographi to evaluate the transverse and longitudinal arch of the foot. The plantar pressure distribution was recorded using I-Step foot scanner in erect standing position for 30 second on the foot scanning plate. The result analyzed using the Bravais-Pearson's correlation coefficient (R).

\section{Results}

Abnormal posture were observed in $79 \%$ of children, while $12 \%$ of assess children have no deviation in anklefoot complex. There is no significant correlation between sex and pronation ( $\mathrm{R}-0.13)$, age and posture abnormality

National Sports Academy, Sofia, Bulgaria 